\title{
The histogenesis of carcinoid tumours of the rectum
}

\author{
N. M. GIBBS \\ From the Royal Surrey County Hospital, Guildford, and St. Mark's Hospital, London
}

SYNOPSIS 'Carcinoid' tumours of the rectum have been described which are classified on histo logical appearances into three main varieties: 'true' carcinoid or argentaffinoma, 'atypical' or non argentaffin carcinoid, and 'composite carcinoid. The histogenesis of these tumours is discussed an it is suggested that non-argentaffin carcinoids of the rectum have an essentially similar histogenesis to certain tumours of the lung, pancreas, and gastrointestinal tract. The difference in growth $\dot{\mathrm{e}}_{\mathrm{N}}^{\circ}$ pattern, and staining reactions are a reflection of differing directions and levels of differentiation of the parent epithelium. The functional implications of this hypothesis are discussed.

Tumours called 'carcinoid' have been described in many organs including the lungs, gall bladder, pancreas, stomach, intestines, and rectum. The majority show the argentaffin reaction and merit the label 'argentaffinoma'. There are some tumours, however, notably those in the lung and rectum, which show variations in morphology.

The object of this paper is to describe the histology of five primary 'carcinoid' tumours of the rectum, one primary adenocarcinoma of the rectum with lymphatic metastases histologically indistinguishable from rectal carcinoid, and one sacrococcygeal teratoma containing a carcinoid tumour of rectal type, and also to discuss the relationship between these tumours and carcinoids elsewhere in the gastrointestinal tract, and to establish a link with adenocarcinoma of the rectum and certain epithelial tumours of the lung and pancreas.

\section{REVIEW OF THE LITERATURE}

Lubarsch (1888) separated a group of gastrointestinal epithelial tumours which were dissimilar to typical adenocarcinomas in their morphology and clinical course. These tumours were later named 'carcinoid'. The 'true' carcinoid tumour, in common with the Kultschitzky cell, has the property of reducing ammoniacal silver. However, some tumours of the alimentary tract which appear to be typical carcinoids do not reduce ammoniacal silver and Erspamer (1939) believed that this type arose from the Kultschitzky cells in the 'pre-enterochrome' phase before the argentaffin granules had been formed. In addition there were tumours confined almost entirely

Received for publication 6 November 1962. to the rectum which varied in morphology and stain ing properties from the true carcinoid. This variety was fully described by Stout (1942) and showed P\$ tendency to a tubular or ribbon pattern and was argentaffin negative. Morson (1958) introduced the term 'atypical' carcinoid to describe this tumour The first malignant atypical carcinoid of the rectun was reported by Siburg (1929).

A review of the literature has shown 172 cases o: carcinoid tumour of the rectum of which 45 casesf were stated to be malignant tumours. The argentaffin? reaction was recorded in 109 cases but only 13 tumours contained argentaffin granules. Other. histochemical reactions were described infrequentlyo However the validity of some of the argentaffing reactions has been questioned by Lillie and Glenneg (1960).

\section{MATERIALS AND METHODS}

The seven cases to be described were investigated at the Royal Surrey County Hospital, Guildford (case 3), an St. Mark's Hospital, London (cases 1, 2, 4, 5, 6, and 7) between 1953 and the present time. Case 5 of this series was briefly reported by Gabriel and Morson (1956). If general the criteria laid down by Lillie and Glenner (1960) to obviate technical failure in the argentaffin reactiog were followed. Argentaffin cells were identified in norma mucosa adjacent to the tumours in cases 1 to 6 inclusive The tissues were fixed immediately in $10 \%$ formol salins and pinned out on a cork board or metal frame. Blocks of tissue were selected, processed, and embedded in paraffip wax. Sections were cut at $5 \mu$ and stained routinely bo Ehrlich's haematoxylin and eosin. Special stains use included periodic-acid Schiff's reagent, and Southgate mucicarmine for glandular mucin; van Gieson's methog for connective tissue; Fontana's silver impregnation and 
the diazo method for enterochromaffin granules, both after treatment of the sections with oxalic acid; and Perls's reaction for haemosiderin. Histochemical tests for the fat content of the tumours were not done.

\section{DESCRIPTION OF CASES}

CASE 1 E.C.D., a man aged 56 years, complained of bleeding from haemorrhoids. A small polyp was found incidentally during sigmoidoscopy $14 \mathrm{~cm}$. from the anus and was removed. There has been no recurrence a year after removal.

Microscopy The sessile polyp was formed by a tumour of alveolar structure which appeared to arise from the base of the crypts of Lieberkühn. The tumour spread into the submucosa where it promoted both a proliferation of smooth muscle fibres and connective tissue. However, in places, the tumour cells extended into the lumen of the glands to form polypoid excrescences. The tumour had a glandular pattern (Figs. 1 and 2), reduced ammoniacal silver, and gave a positive diazo reaction at the site of the budding from the crypts and in defined areas elsewhere in the tumour. However, much of the tumour gave a negative reaction to these specific stains. Mucin was not demonstrated in the tumour.

Pathological diagnosis This tumour is an example of the true carcinoid or argentaffinoma.

CASE 2 K.B., a women aged 49 years, complained of periodic attacks of diarrhoea for two years. Sigmoidoscopy showed a small submucous yellowish growth 6 to 8 $\mathrm{cm}$. from the anus which was excised. Qualitative tests for urinary excretion of 5-hydroxyindole acetic acid (5H.I.A.A.) were negative three months later.

Microscopy There was a small mucosal tumour of the rectum which arose in apposition to the rectal crypts although no direct continuity was established. The superficial parts of the tumour consisted of groups of cells that mimicked an epidermal basal cell tumour in pattern (Fig. 3). The deeper portions of the tumour, however, had a pronounced alveolar pattern with infolding of cells causing a convoluted appearance rather like a pile of ribbon (Fig. 4). No mucin or chromaffin granules were demonstrated.

Pathological diagnosis This is an example of the benign atypical carcinoid of rectum.

CASE 3 H.L., a man aged 80 years, complained of difficulty in defaecation for two months. A pelvic mass was felt on rectal examination, and a rectal tumour, which was adherent posteriorly to the sacrum, was removed by abdomino-perineal resection in one stage. No hepatic metastases were seen. The patient died three weeks after operation and permission for necropsy was refused. Postoperative qualitative tests for urinary 5-H.I.A.A. were negative.

Description of tumour The rectum, anal canal $(28 \mathrm{~cm}$.$) ,$ and peri-anal skin had been removed with the tip of the coccyx. There was a sessile polyp $(1 \times 1 \cdot 2 \mathrm{~cm}$. $)$ on the posterior aspect of the rectum which was situated $1.5 \mathrm{~cm}$. from the pectinate line. A haemorrhagic mass $(4.5 \times 4$ $\mathrm{cm}$.), apparently in continuity with the polypoid tumour, was attached to the posterior aspect of the rectum in the presacral tissues. A lymph gland $(1.5 \times 2 \mathrm{~cm}$.) removed from the pelvic mesocolon was also included.

Microscopy The sessile polyp was formed by mucosal tumour which raised and stretched the overlying epithelium. Centrally the polyp was covered by a single stretched layer of columnar epithelium and there was no ulceration. The tumour was epithelial in origin and in close association with the stretched glandular crypts but no direct connexion was demonstrated. Here the tumour cells were grouped in solid clumps with peripheral pallisading (Fig. 5). Deeper parts of the tumour invaded the hypertrophied muscularis mucosae and extended through all coats of the rectum into the presacral tissues. The tumour external to the muscularis mucosae assumed a variable pattern with long columns of cells forming a predominating lacework or ribbon pattern (Fig. 5). This portion of the tumour was lying in a highly vascular matrix so that tumour cells appeared to be proliferating in pools of blood. Areas of tumour showed necrosis and haemosiderin deposits were conspicuous around the extremities of the growth. There was some nuclear pleomorphism, but mitoses were scanty. Tumour infiltrating the presacral tissues made identification of lymph glands difficult but metastases were found in four glands. In addition the gland removed from the pelvic mescolon was almost completely replaced by tumour. No venous invasion was demonstrated. The tumour cells were consistently argentaffin and diazo negative. No mucin was demonstrated by Southgate's mucicarmine but some dubious staining was given by the P.A.S. method.

Pathological diagnosis This is an example of a malignant atypical carcinoid tumour of the rectum with lymphatic metastases.

CASE 4 K.G., a man aged 46 years, complained of bleeding per rectum for nine months. A hard, irregular mass $(2 \mathrm{~cm}$. diameter) was felt on the anterior wall of the rectum and a biopsy was taken. A synchronous combined excision of the rectum was done eight days after admission from which he made a satisfactory recovery.

Description of tumour The specimen $(45 \mathrm{~cm}$.) consisted of lower pelvic colon, rectum, and anal canal. An ulcer was present in the lower third of the rectum at the site of the previous biopsy. The ulcer was shaped rike an inverted triangle $(5 \mathrm{~cm}$. across at its longest axis) with the apex reaching the pectinate line. Six lymph nodes were dissected.

Microscopy Examination of the original biopsy was made in conjunction with the operation specimen. The mucosal tumour had raised the rectal mucosa to form a sessile polyp and there was central ulceration. The tumour cells were very close to the rectal crypts but no direct connexion was demonstrated. The cells were mainly arranged in groups adjacent to the crypts (Fig. 6), but where the tumour penetrated the muscularis mucosae there was a gradation to a ribbon-like pattern. Muscle had not been invaded. The tumour had a very intimate vascular circulation and extensive deposits of haemosiderin were present throughout. Two of the six lymph glands contained extensive metastases of tumour which had a ribbon arrangement (Fig. 7). The 'ribbons' were formed by a 


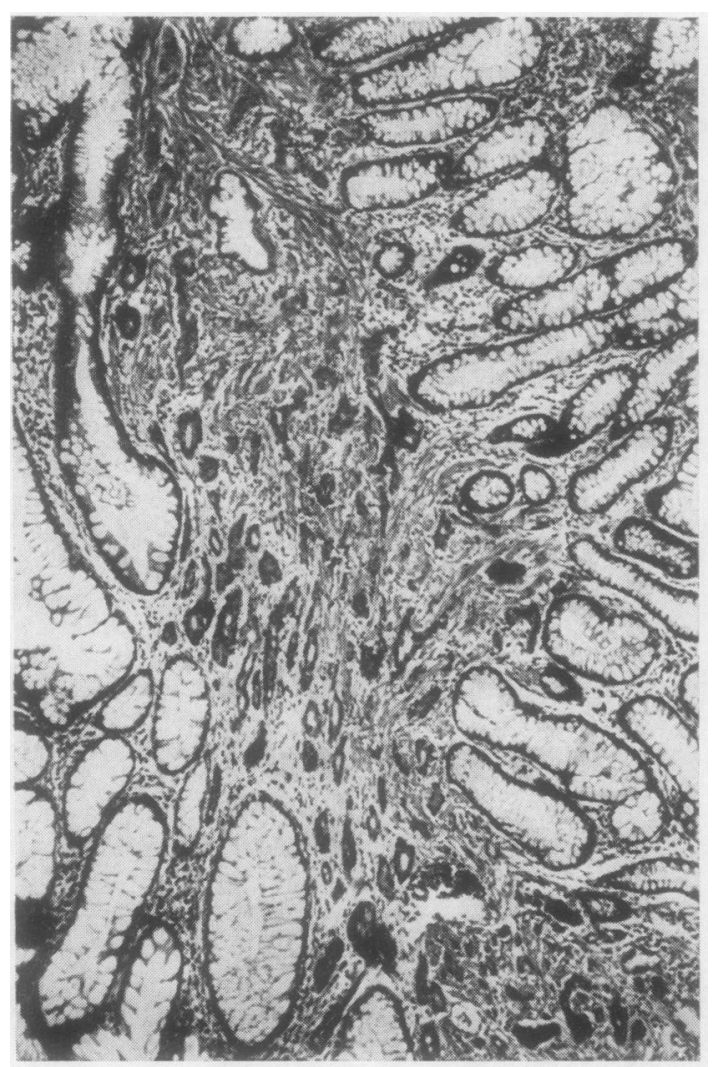

FIG. 1

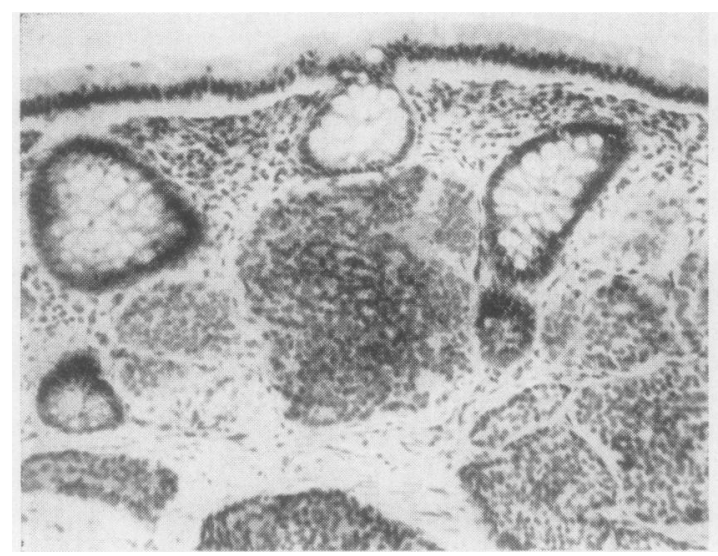

FIG. 3

FIG. 1. Case 1. Haematoxylin and eosin $\times 26$.

FIG. 2. Case 1. Fontana $\times 68$.

FIG. 3. Case 2. Haematoxylin and eosin $\times 150$.

FIG. 4. Case 2. Haematoxylin and eosin $\times 200$.

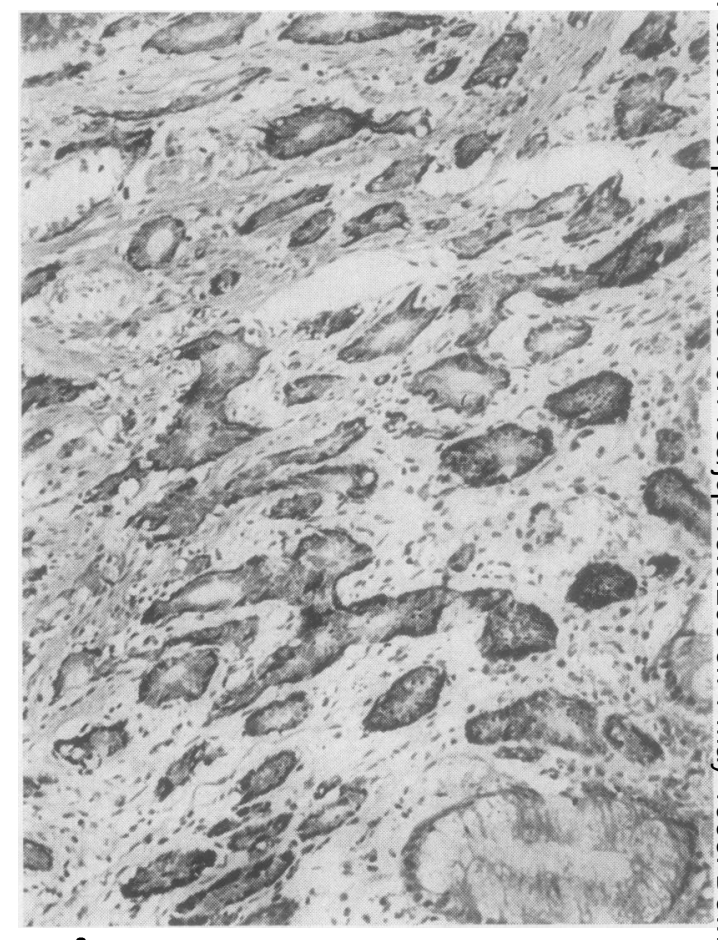

FIG. 2

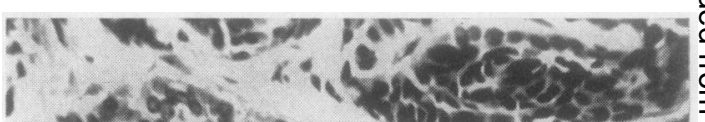

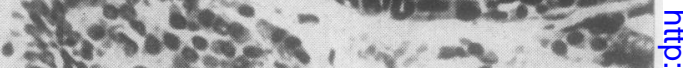

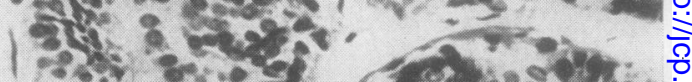

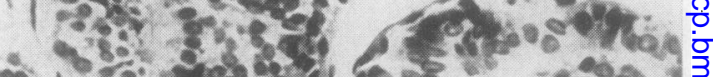

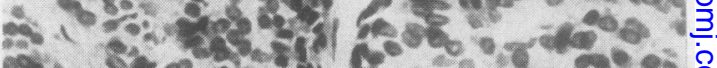

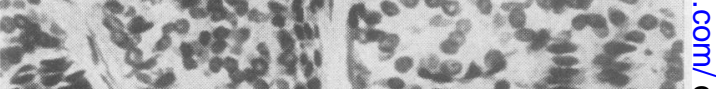

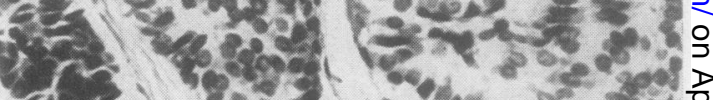

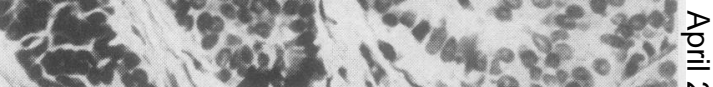

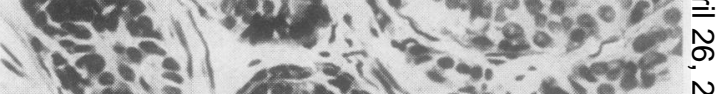

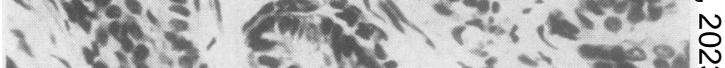
(1) हो.

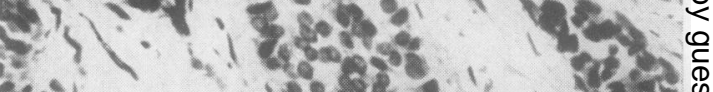

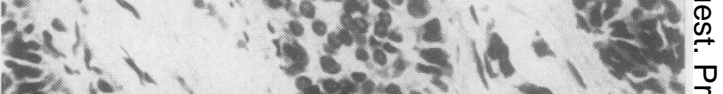
3 .

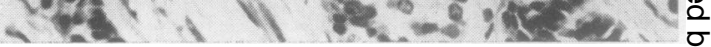
FIG. 4 


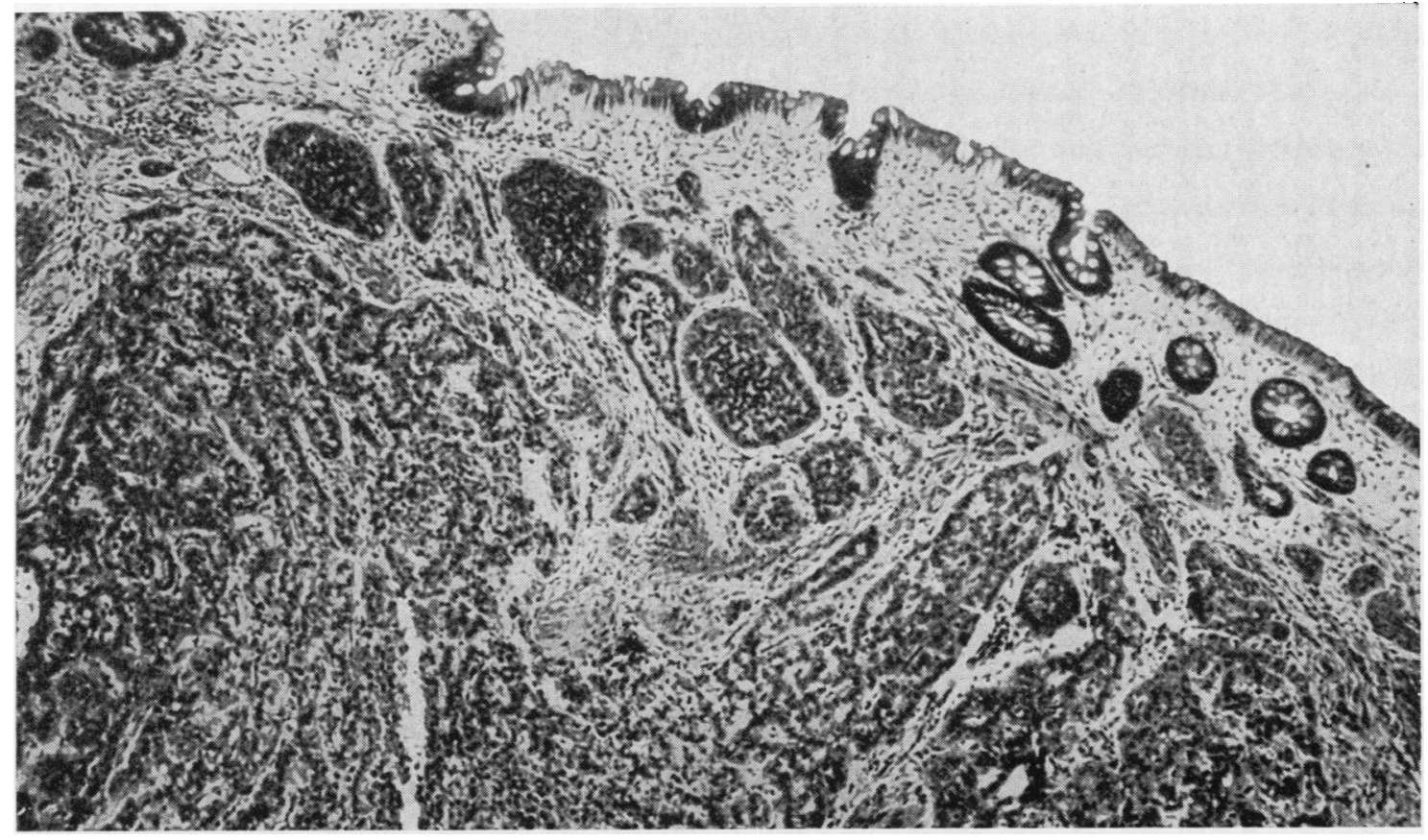

FIG. 5. Case 3. Haematoxylin and eosin $\times 40$.

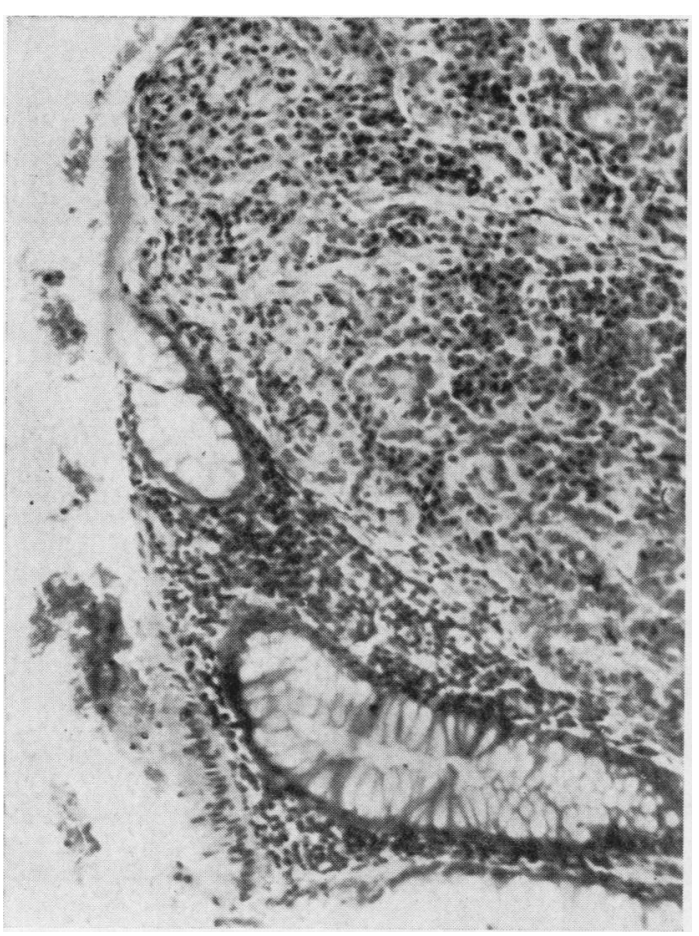

FIG. 6. Case 4. Haematoxylin and eosin $\times 68$.

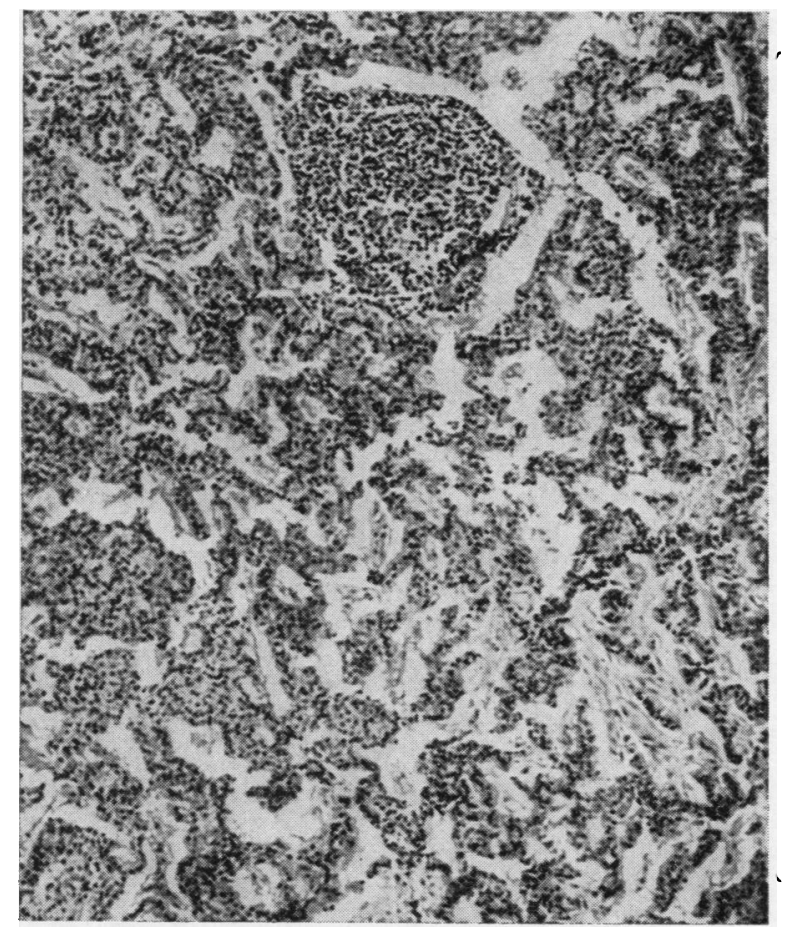

FIG. 7. Case 4. Haematoxylin and eosin $\times 40$. 
single or double layer of oval or elongated cells which showed slight pleomorphism. Mitoses were very infrequent. The tumour in the lymph glands appeared to be growing in lakes of blood and conspicuous deposits of haemosiderin were present, particularly at the periphery. The tumour cells were argentaffin and diazo negative and no mucin was demonstrated.

Pathological diagnosis The case is similar to case 3 and is a malignant atypical carcinoid tumour of the rectum with metastases in the lymph glands.

CASE 5 L.A., a man aged 48 years, had attended St. Mark's Hospital for treatment of recurrent rectal bleeding. A small friable and ulcerated neoplasm of the rectum was seen at a sigmoidoscopy. The rectum was removed by perineo-abdominal excision in one stage. There were two metastases (larger $5 \mathrm{~cm}$. diameter) in the right lobe of the liver, from which a biopsy was taken. He died two years and eight months after operation with multiple metastases. Pre-operative and repeated postoperative qualitative examinations of the urine for 5H.I.A.A. gave negative results.

Description of tumour There was a deeply ulcerated tumour $(2.5 \mathrm{~cm}$. in diameter) encircling half of the upper third of the rectum extending to within $12 \mathrm{~cm}$. of the ano-rectal junction. The peri-rectal tissues were extensively invaded.

Microscopy The centre of the ulcer was formed by tumour which replaced the rectal glands (Fig. 8). The superficial parts of the tumour had a glandular pattern and showed conspicuous mucin secretion and the formation of mucous cysts (Fig. 9). Peripherally the tumour could be seen budding from the rectal crypts and sometimes formed multiple layers of cells on the walls of the crypts. Centrally, however, the tumour invaded the muscle of the rectum forming columns of cells which in places resembled a ribbon pattern (Fig. 10). There was a dense connective tissue reaction around the tumour. The argentaffin and diazo reactions were positive in some parts of the tumour, particularly in the superficial layers and at the periphery of the clumps of tumour cells and where the tumour alveoli were small and compressed by fibrous tissue. Secretion of mucin was most prominent in the superficial layers but was demonstrated at all levels. No venous growth was demonstrated. Nine of the 18 lymph nodes dissected showed metastases. The liver biopsy showed similar tumour.

Pathological diagnosis This is an example of a malignant carcinoid tumour with a composite structure showing conspicuous secretion of mucin and positive chromaffin reactions.

CASE 6 A.J., a man aged 48 years, complained of diarrhoea for three months. An ulcerating growth on the anterior wall of the rectum was seen and a biopsy was taken. The rectum was resected by an abdomino-perineal operation.

Description of tumour The resected bowel consisted of sigmoid colon, rectum, and anal canal $(30 \mathrm{~cm}$. in length). An ulcerated tumour with ill-defined margins $(6.5 \mathrm{~cm}$. in diameter) completely encircled the upper third of the rectum. The lower edge was $12.5 \mathrm{~cm}$. above the dentate line. A polyp was present in the pelvic colon.

Microscopy The tumour was an adenocarcinoma of average grade of malignancy (Fig. 11), secreting smal amounts of mucin. The polyp in the pelvic colon was an? adenoma. All coats of the bowel wall were involved witio invasion of the peri-rectal fat. Lymphatic metastases were present in two of the 18 haemorrhoidal glands examined $\stackrel{\mathcal{S}}{\stackrel{5}{ }}$ These two metastases, one of which was $5 \mathrm{~cm} \Phi$ distal to the lower border of the tumour, had a differenty pattern from the primary tumour (Fig. 12). This pattern? resembled a carcinoid tumour of the atypical type and consisted of ribbons of cells set in a variable stroma which was sometimes vascular and sometimes fibrous $\bar{\omega}$ Mitoses were present in the main tumour but were absent from these two metastases. The argentafin and diazळ reactions were negative.

Pathological diagnosis Adenocarcinoma of the rectum with lymph gland metastases resembling atypical carcinoid tumour of the rectum.

CASE 7 J.C., a man aged 63 years, developed a cysticswelling in the region of the coccyx which later discharged $Z$ pus. A sinus was found at the extreme bony limit of the sacrum in communication with a presacral tumour. The tumour was removed.

Description of tumour The tumour $(6.5 \times 3.5 \times 3 \mathrm{~cm} .)^{\omega}$ was oval in shape and the cut surface revealed a smalp abscess in continuity with the sinus.

Microscopy The tumour was a teratoma consisting of dense connective tissue and smooth muscle containingo some glandular structures. The most prominent glandularo structure was intestinal mucosa (Fig. 13), which was well differentiated with high columnar epithelium and promi- $\overrightarrow{\bar{O}}$ nent goblet cells. The mucosa was arranged as villous 3 processes showing occasional branching. Argentaffin and $\mathcal{F}$ Paneth cells were not demonstrated. At one end theo columnar epithelium showed transition to a thick layer of stratified squamous epithelium. The connective tissue in juxtaposition to the mucosa was infiltrated by epithelialo tumour arranged in a ribbon pattern, one or two cell layers in thickness and sometimes forming retiform or $\bar{\rho}$ alveolar variations (Fig. 14). Mitoses were not present and 3 the argentaffin and diazo reactions were negative. In 0 addition numerous smooth muscle fibres were present. Elsewhere the teratoma contained a number of cysts $\frac{7}{0}$ lined by flattened squamous, columnar, or cuboidal epithelium. A small abscess was also present.

Pathological diagnosis Sacrococcygeal teratoma containing atypical carcinoid tumour of rectal type.

\section{CLASSIFICATION}

The histological variants of carcinoid tumour of the rectum may be classified as follows:-

'TRUE' CARCINOID OR ARGENTAFFINOMA This tumour (case 1) is uncommon in the rectum but examples $\frac{O}{\mathbb{P}}$ have been described by Brunschwig (1933), by $\frac{\varrho}{\sigma}$ Rigdon and Fletcher (1946), and by Morson (1958). 


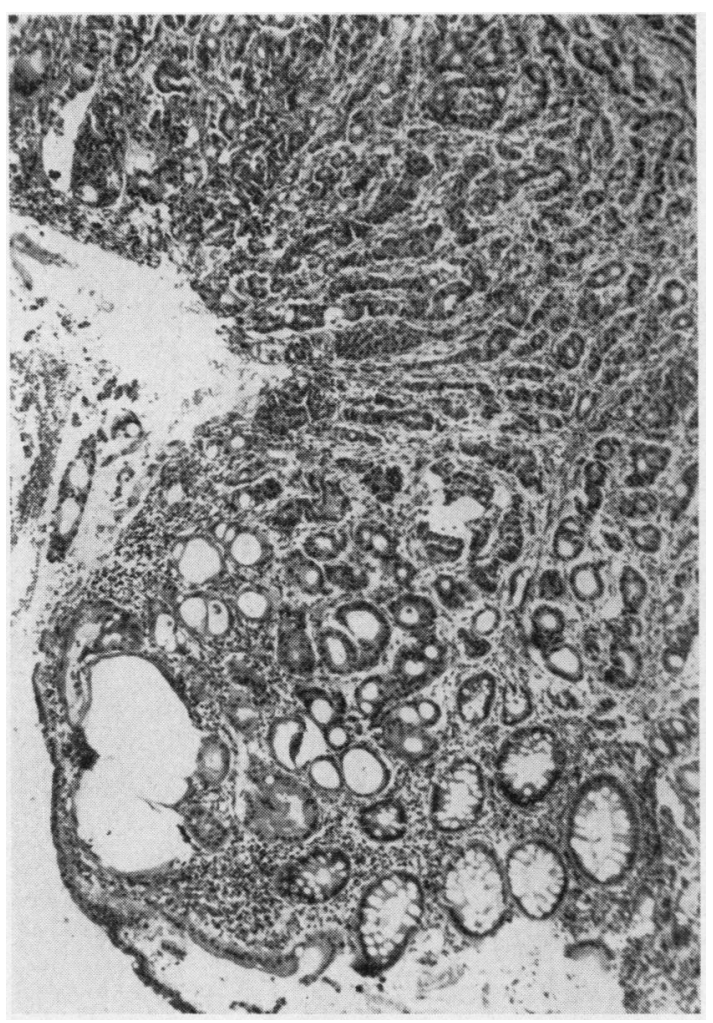

FIG. 8. Case 5. Haematoxylin and eosin $\times 26$.

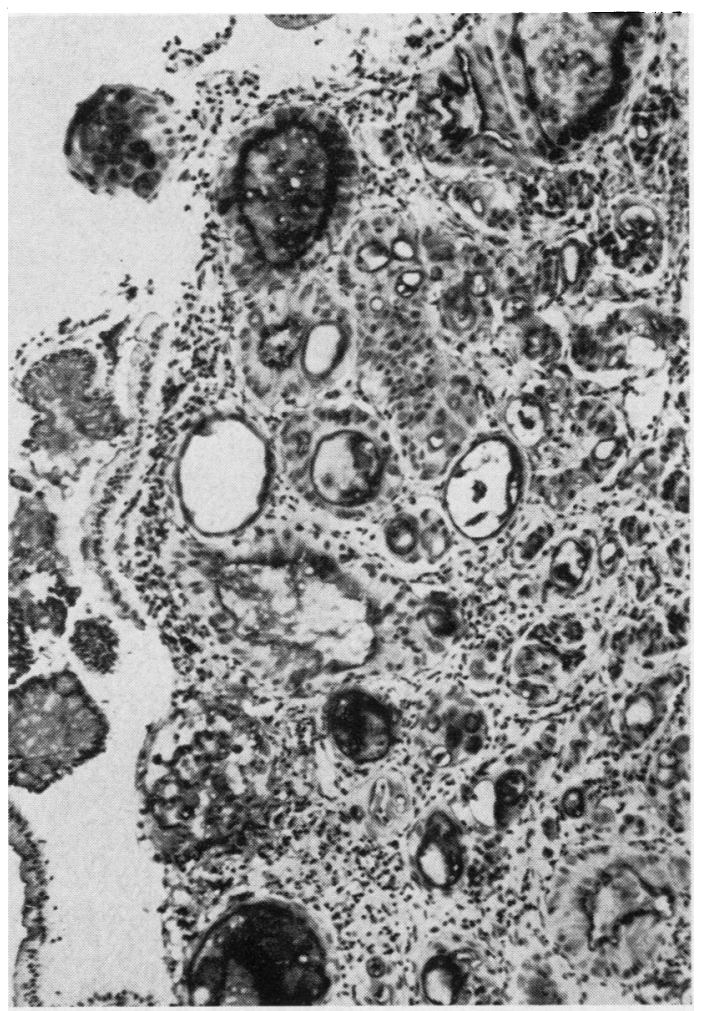

FIG. 9. Case 5. Mucicarmine $\times 68$. 


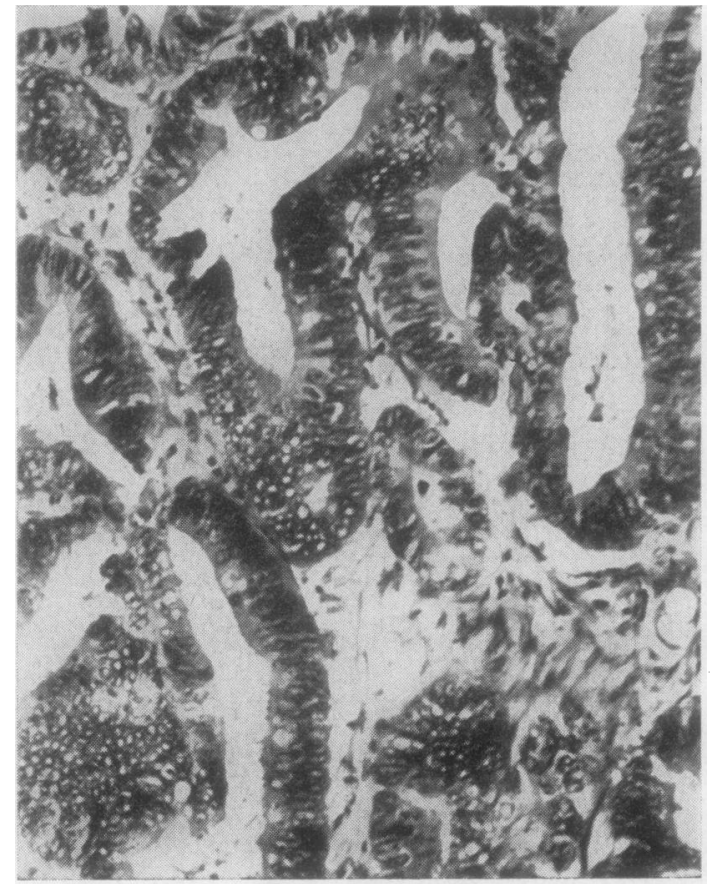

FIG. 11. Case 6. Adenocarcinoma of rectum. Haematoxylin and eosin $\times 68$.

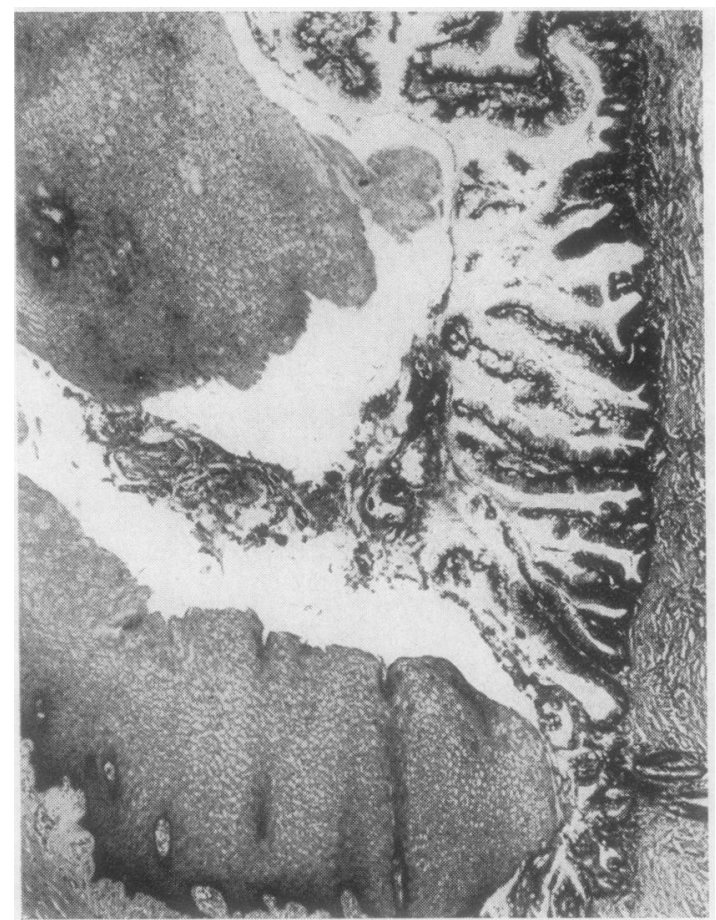

FIG. 13. Case 7. Haematoxylin and eosin $\times 26$.

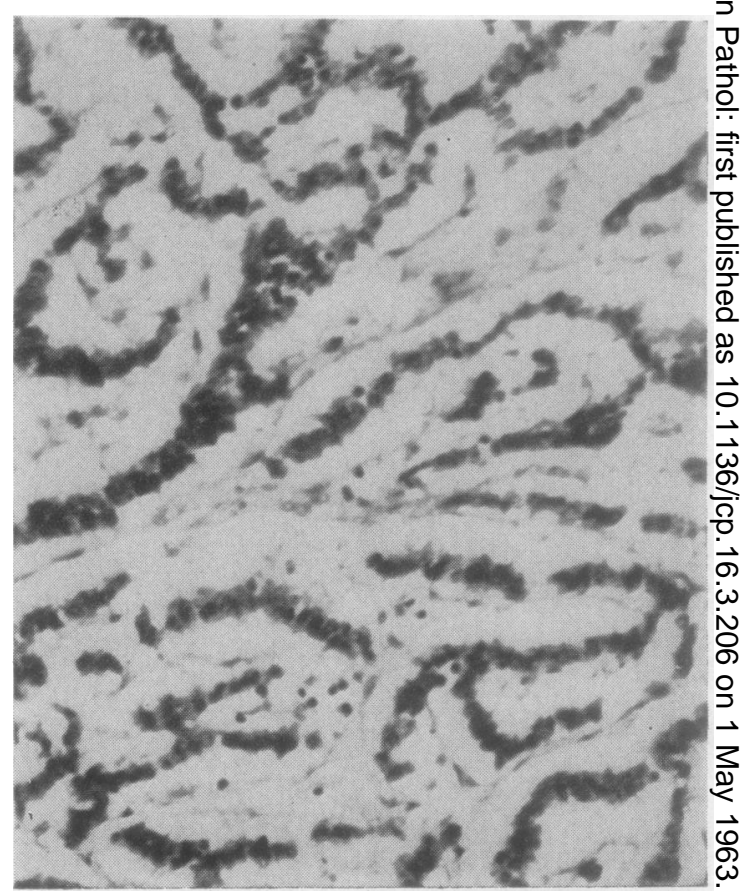

FIG. 12. Case 6. Metastases resembling atypical carcinoid in regional lymph glands. Haematoxylin and eosin $\times 100$.

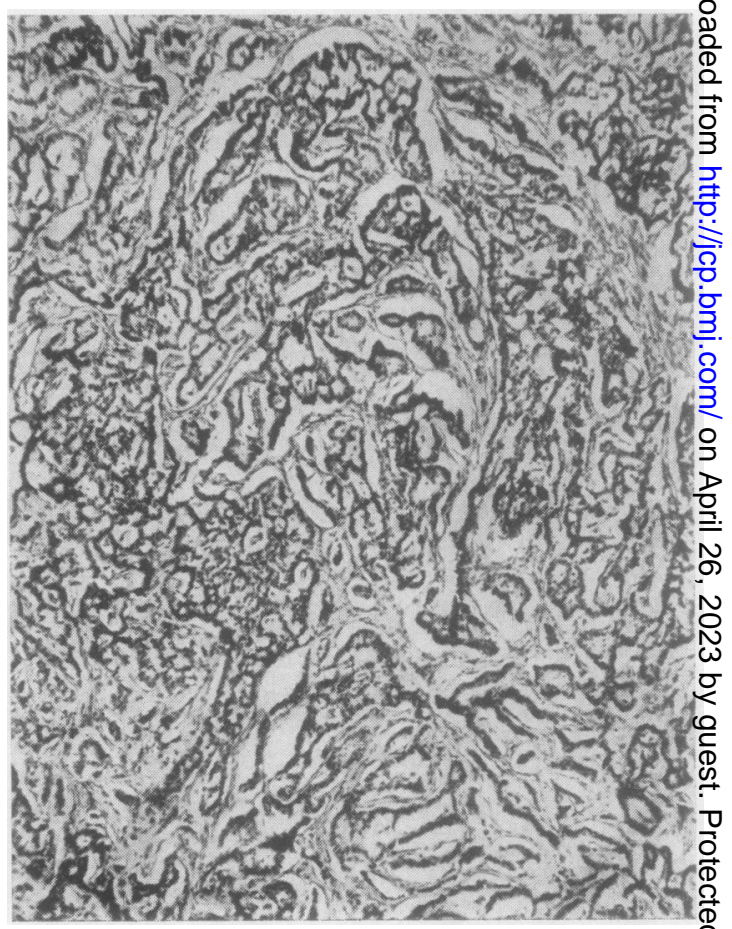

FIG. 14. Case 7. Haematoxylin and eosin $\times 26$. 
'ATYPICAL' CARCINOID (NON-ARGENTAFFIN) Benign atypical carcinoid (case 2) is the variety found most often in the rectum and comprised 15 of the 21 cases in the St. Mark's Hospital series of 'atypical' carcinoids (Morson, 1958), and malignant atypical carcinoid was found in cases 3 and 4.

In sacrococcygeal teratoma (case 7) Atypical carcinoid was found in two cases during a review of teratomas at St. Mark's Hospital and no similar description has been found in the literature. Argentaffinoma in teratomas has been described, particularly in the ovary in association with alimentary epithelium. Evans, Harris, and McDougall (1959) described a case and reviewed seven others.

In adenocarcinoma of rectum (case 6) The occurrence of lymphatic metastases characteristic of atypical carcinoid associated with adenocarcinoma of the rectum has not been described in the literature. However, in some small cell and anaplastic carcinomas occasional areas of tumour may bear some resemblance to malignant atypical carcinoid (Morson, 1962).

'COMPOSITE' CARCINOID OF THE RECTUM (CASE 5) No other examples of this tumour have been found in the literature although Siburg (1929) demonstrated mucin in a malignant atypical carcinoid. Occasional argentaffin cells may be found in adenocarcinomas of the alimentary tract so that the presence of argentaffin cells does not automatically establish the diagnosis of carcinoid tumour.

\section{DISCUSSION}

The true carcinoid tumour or argentaffinoma arises from the Kultschitzky cells but it cannot be assumed that the chromaffin-negative tumours have a similar origin. Histological studies indicate that carcinoids arise from the basiglandular cells of the mucosa. Three types of cells are found in the glandular crypts, namely, the non-secretory agranular, Kultschitzky, and Paneth cells. Morson (1958) suggested that the atypical carcinoid arises from the Kultschitzky cells before the ability to produce granules has been acquired. The basiglandular cells and the mature goblet cell have a common origin embryologically from the primitive entoderm, and this could provide an explanation for the varying histological appearances of these tumours. Differentiation in dissimilar directions may produce a composite tumour (case 5), with some cells containing argentaffin granules and others secreting mucin. This hypothesis is strengthened by case 6 where an apparently typical adenocarcinoma produced lymphatic metastases characteristic of atypical carcinoid tumour. Furthermore adenocarcinomas of the alimentary tract have been described which contain a few argentaffin cells (Cordier, 1924; Hamperl, 1927; Masson and Martin, 1928). The histological similarity between some small cell and anaplastic adenocarcinomas and malignant atypical carcinoid tumours may be a further example of the variable differentiation of the basiglandular cells, although it is well known that malignant epithelial tumours assume a variety of histological patterns. Further evidence of the genesis of atypical carcinoid tumour is provided by the demonstration of this tumour (case 7) in two cases of sacrococcygeal teratoma.

There has been much discussion in the pathological literature concerning the histogenesis of bronchial adenomas but the recognition of the carcinoid syndrome in some cases of metastasizing bronchial adenoma has shown that some of them are carcinoid tumours. Luparello and McAllister (1961) reviewed eight cases of the carcinoid syndrome and noted that the argentaffin reaction could only be demonstrated in two cases, although the more specific diazo reaction was not done. A study of the published cases of metastasizing bronchial carcinoids showed that the majority more closely resembled atypical carcinoid of rectal type than true argentaffinomas. A link can be established between bronchial and alimentary carcinoids on embryological grounds, as both the bronchial and the alimentary tracts are derived from the primitive entoderm in early foetal life. The pancreas in common with the intestine develops from entoderm. Argentaffin cells are found occasionally in the pancreas, usually in the duct epithelium. True argentaffinomas and non-argentaffin carcinoids have been described in the pancreas (Williams, 1960; Willis, 1953). They may be mistaken for islet-cell tumours (Willis, 1953). Some 'islet-cell' tumours are similar to atypical carcinoids in histological appearance and other points of resemblance are slow growth and the late development of metastases. A number of clinical syndromes have been described in association with islet-cell tumours which do not release insulin, e.g., peptic ulceration of the small intestine (Zollinger and Ellison, 1955), malabsorption syndrome (Maynard and Point, 1958), and diarrhoea and potassium depletion (Verner and Morrison, 1958; Parkins, 1961). An increased histamine excretion has been noted in some cases of the carcinoid syndrome (Sjoerdsma, Weissbach, Terry, and Udenfriend, 1957), and this may provide a link with cases of the Zollinger-Ellison syndrome where gastric hypersecretion may be induced by histamine.

Study of the seven cases described and the additional evidence gained from the study of some epithelial tumours of the lung and pancreas provides evidence of a community of closely related cells with 
a common entodermal origin. These cells include the Kultschitzky and other basiglandular cells of the alimentary tract and they possibly include the Paneth cell. They may exert a functional control over the alimentary and respiratory tracts by endocrine and/ or exocrine secretion. The histological differences between the true and atypical carcinoid tumours are perhaps not merely a matter of tinctorial or morphological variation unrelated to cell function. No record has been found of the carcinoid syndrome in association with malignant atypical carcinoid of the rectum. Nevertheless, the carcinoid syndrome does occur in the non-argentaffin carcinoid of the bronchus and intestine and stomach (Snow, LennardJones, Curzon, and Stacey, 1955; Duncan, Garven, and Gibbons, 1955). A possible explanation for this apparent contradiction, excluding the wide gap that may exist between histological morphology and function, is that the cells of the atypical carcinoid of the rectum may have different but as yet unrecognized endocrine properties. However, the fact that some atypical carcinoids promote a dense local sclerosis of connective tissue is a point in favour of local serotonin release.

The relationship between these specialized cells having been considered, the problem of notation remains. Is it justifiable to name these tumours true, atypical, and composite carcinoid tumours? Oberndorfer (1907) invented the name 'carcinoid' which means by derivation 'like carcinoma', when the nature of the tumour was little understood. A case could be made for naming them entodermal or stem-cell carcinomas, but in a sense, these names are equally applicable to adenocarcinomas. The wary pathologist should abstain from juggling with semantics and it would seem wise to delay changes of nomenclature until the function of these specialized cells is fully understood.

I wish to thank Dr. B. C. Morson for his advice and $\overrightarrow{\overrightarrow{0}}$ encouragement, and the consultant staff of St. Mark's Hospital and the Royal Surrey County Hospital for permission to study their cases. For technical assistance I am $\overline{\bar{D}}$ grateful to Mr. Lloyd Soodeen and Mr. Norman Mackie. $\frac{\omega}{\partial}$

The expenses of this investigation were defrayed from a $₫$ block grant to the Research Department of St. Mark's Hospital from the British Empire Cancer Campaign.

\section{REFERENCES}

Brunschwig, A. (1933). J. Amer. med. Ass., 100, 1171

Cordier, R. (1924). Arch. int. Méd. exp., 1, 59.

Duncan, D., Garven, J. D., and Gibbons, J. L. (1955). Brit. med. J., 2, 1586.

Erspamer, V. (1939). Z. Anat. Entwickl.-Gesch., 109, 586.

Evans, R. W., Harris, H. R., and McDougall, C. D. M. (1959). J. clin. $\dot{\omega}$ Path., 12, 183.

Gabriel, W. B., and Morson, B. C. (1956). Proc. roy. Soc. Med., 49. ᄋे 472.

Hamperl, H. (1927). Virchows Arch. path. Anat., 266, 509.

Lillie, R. D., and Glenner, G. G. (1960). Amer. J. Path., 36, 623.

Lubarsch, O. (1888). Virchows Arch. path. Anat., 3, 280.

Luparello, F. J., and McAllister, J. D. (1961). Ann. intern. Med., 54, 1266.

Masson, P., and Martin, J. F. (1928). Bull. d'Assoc. Franc. Etude Cancer, 17, 139.

Maynar 1, E. P., and Point, W. W. (1958). Amer. J. Med., 25, 456. Morson, B. C., (1958). In Modern Trends in Gastro-enterology, 2nd ser., edited by F. Avery Jones, p. 107, Butterworth, London. (1962). Personal communication.

Oberndorfer, S. (1907). Frankfurt Z. Path., 1, 426.

Parkins, R. A. (1961). Brit. med. J., 2, 356.

Rigdon, R. H., and Fletcher, D. E. (1946). Amer. J. Surg., 71, 822.

Siburg, F. (1929). Frankfurt. Z. Path., 37, 254.

Sjoerdsma, A., Weissbach, H., Terry, L., and Udenfriend, S. (1957). Amer. J. Med., 23, 5.

Snow, P. J. D., Lennard-Jones, J. E., Curzon, G., and Stacey, R. S. (1955). Lancet, 2, 1004.

Stout, A. P. (1942). Amer. J. Path., 18, 993.

Verner, J. V., and Morrison, A. B. (1958). Amer. J. Med., 25, 374

Williams, R. (1960). Brit. med. J., 1, 28.

Willis, R. A., (1953). Pathology of Tumours, 2nd ed. p. 451. Butterworth, London.

Zollinger, R. M., and Ellison, E. H. (1955). Ann. Surg., 142, 709. 